\title{
A PROBLEMÁTICA DOS RESÍDUOS SÓLIDOS URBANOS EM TEFÉ, AMAZONAS
}

\section{The issue of urban solid waste in Tefé, Amazonas State, Brazil}

\author{
Alexandre Donato da Silva \\ Mestre em Ciências do Ambiente e Sustentabilidade na Amazônia/PPGCASA/UFAM \\ Manaus/AM - Brasil \\ donatoam@gmail.com \\ Eduardo da Silva Pinheiro \\ Professor no Departamento de Geografia/UFAM \\ Manaus/AM - Brasil \\ pinheiro@ufam.edu.br
}

Artigo recebido para publicação em 06/01/2010 e aceito para publicação em 14/05/2010

RESUMO: $\quad$ A infraestrutura disponivel em diversos municípios da Amazônia impõe dificuldades para realizar os serviços de gerenciamento dos resíduos sólidos urbanos, além do cumprimento da legislação ambiental. O objetivo deste trabalho foi analisar, sob a ótica da legislação ambiental e considerando as particularidades fisiográficas da região amazônica, as alternativas locacionais para a disposição dos resíduos sólidos urbanos no município de Tefé, AM. Como suporte à decisão foi utilizado a análise multicritério Weighted Overlay - ArcGIS. Constatou-se que mesmo existindo alternativas locacionais para a instalação de aterro sanitário em Tefé, é necessário que a Resolução CONAMA nº 04/95 seja adaptada para a realidade de infraestrutura do município no que tange a categoria do seu aeroporto e a Área de Segurança Aeroportuária. A exigência de escoar os resíduos sólidos urbanos além de 20 km a partir do centro geométrico do aeroporto exige a construção de estrada pavimentada de mais de $7 \mathrm{~km}$ de extensão, o que significaria impacto econômico e ambiental ao município pela necessidade de desmatar significativa área de floresta.

Palavras-chave: Amazônia. Lixo. Suporte à decisão. Leis ambientais.

ABSTRACT: The accessible infrastructures of several Amazonian counties result in difficulties for urban solid waste management due to the attendance of the environmental legislation. The objective of this study was the analysis, under the viewpoint of the environmental legislation and, considering the physiographical features of the Amazonian region, the alternatives of sites for final disposal of urban solid waste in the municipality of Tefé, in the Amazonas State, Brazil. Also, characterize the collecting conditions and final disposal of solid waste of the county. As decision making was used a multicriteria analysis by Weighted Overlay - ArcGIS. While alternatives exist, sites for the installation of landfill in Tefé, an adaptation of the CONAMA Directive number 04/95 to the reality of the city infrastructure is necessary, related to the category of airport and its security. The requirement of disposing municipal waste beyond $20 \mathrm{~km}$ from the geometric center of the airport requires the construction of paved road for more than 7 $\mathrm{km}$ long, which would mean environmental and economic impact to the city since it would be necessary deforesting significant forest area.

Keywords: Amazon. Waste. Decision making. Environmental laws. 


\section{INTRODUÇÃO}

A disponibilidade de locais para a disposição de resíduos sólidos é um problema crescente nos municípios brasileiros, uma vez que estas áreas devem atender critérios de ordem social, econômica e ambiental (SAMIZAVA et al., 2008). Há um consenso entre diversos autores (BIDONE e POVINELLI, 1999; TENÓRIO e ESPINOSA, 2004; BOSCOV, 2008) que o aterro sanitário é uma das modalidades de disposição final de resíduos sólidos urbanos mais adequadas, pois é uma estrutura de engenharia que impede a poluição do ambiente (impermeabilização do solo, coleta e tratamento do chorume, coleta e queima ou aproveitamento do biogás, sistemas de monitoramento ambiental topográfico e geotécnico).

Para Monteiro et al. (2001), a escolha de um local para a implantação de um aterro sanitário não é tarefa simples, devido ao grau de urbanização das cidades e também à ocupação intensiva do solo do seu entorno. $\mathrm{O}$ alto grau de ocupação restringe a disponibilidade de áreas ideais para a implantação de aterros sanitários próximos aos locais de geração dos resíduos sólidos, assim como com as dimensões requeridas suficientes para atender às necessidades dos municípios.

Nas cidades das calhas dos rios amazônicos a relação entre infraestrutura municipal e o gerenciamento dos resíduos sólidos urbanos constitui uma problemática. De um modo geral, há deficiência nos serviços de coleta e disposição final dos resíduos. A coleta é prejudicada, principalmente, pela dificuldade de acesso dos caminhões de recolhimento dos resíduos às áreas impróprias para a ocupação urbana. Geralmente, essas áreas alagam durante o período de cheia dos rios, os quais são transformados em vazadouros dos resíduos diretamente lançados das moradias (palafitas). Durante esse período, que coincide com a época das chuvas na região, a ausência de estradas pavimentadas impossibilita o transporte dos resíduos até área apropriada para a sua disposição final, que na maioria dos casos também ocorre de forma imprópria (lixões) (SILVA, 2009).

Outros problemas, considerados também graves do ponto de vista ambiental, são complicadores no gerenciamento de resíduos sólidos urbanos nas cida- des das calhas dos rios amazônicos. A complexidade hidrográfica da região e os solos de recente formação, além da vasta floresta tropical, nem sempre permitem dispor os resíduos sólidos em situações ideais, segundo a legislação ambiental brasileira. O conjunto destes aspectos foi descrito por Silva e Schor (2007) no município de Tefé, região do médio rio Solimões, no Estado do Amazonas. A cidade produziu cerca de 20 toneladas diárias de resíduos sólidos, entre os anos de 2006 e 2007, e passou por período que ficou conhecido como a "crise do perigo aviário". Neste período, a inadequação da forma de disposição final dos resíduos sólidos da cidade, em depósitos a céu aberto e próximos da cabeceira da pista do aeroporto, fez com que a justiça determinasse a paralisação das operações de navegação aérea pela iminência de choque entre aeronaves e pássaros que eram atraídos ao lixão em busca de matéria orgânica. A crise do perigo aviário em Tefé chamou a atenção para a Resolução CONAMA $n^{\circ}$ 04/95 que estabelece a Área de Segurança Aeroportuária (ASA) de $20 \mathrm{~km}$ de raio a partir do centro geométrico do aeroporto do município. Na ASA não são permitidas atividades que atraiam pássaros e os lixões constituem uma fonte de alimentos para aves.

O principal problema em Tefé é identificar um local para dispor os resíduos sólidos além de $20 \mathrm{~km}$ do centro geométrico do aeroporto, uma vez que as estradas para além da área urbana são poucas e de curta extensão. Uma solução para a problemática dos resíduos sólidos do município é a construção de um aterro sanitário. Andrade (2007) relaciona critérios que possibilitam identificar áreas potenciais para a implantação de aterros sanitários na Amazônia, dividindo-os em quatro critérios: ambiental (poluição, terra para cobertura e desmatamento), econômico (distância de transporte, custo do terreno, infraestrutura), social (vizinhança, saúde e segurança pública e modificação nos padrões socioculturais) e técnico (acesso, capacidade, topo-hidro-geologia). Devido à complexidade e ao grande número de fatores que devem ser considerados para estabelecer áreas propícias para a instalação de aterros sanitários, as técnicas de suporte a decisão apoiadas em Geotecnologias (Sistema de Informações Geográficas; Sensoriamento remoto e Sistema de Posicionamento Global) têm consistido em uma importante ferramenta de análise e 
planejamento destes locais, como demonstraram trabalhos realizados por Weber e Hasenack (2000), Calijuri et al. (2002), Rocha et al. (2004), Biana (2007), Santos e Girardi (2007), Samizava et al. (2008) e Moreira et al. (2008).

O objetivo deste trabalho foi analisar, sob a ótica da legislação ambiental e considerando as particularidades fisiográficas da região amazônica, as alternativas locacionais para a disposição dos resíduos sólidos urbanos no município de Tefé.

\section{MATERIAL E MÉTODOS}

\section{Caracterização da área de estudo}

O município de Tefé possui uma área de 23.704 $\mathrm{km}^{2}$, está localizado entre as coordenadas geográficas $03^{\circ} 15^{\prime} 39^{\prime \prime}$ a $05^{\circ} 34^{\prime} 22^{\prime \prime}$ Sul e $64^{\circ} 04^{\prime} 12^{\prime \prime}$ a $68^{\circ} 58^{\prime} 32^{\prime \prime}$ Oeste de Greenwich (FIGURA 1). A área urbana do município localiza-se à margem direita da foz do rio Tefé. A inexistência de estradas que cheguem a Tefé

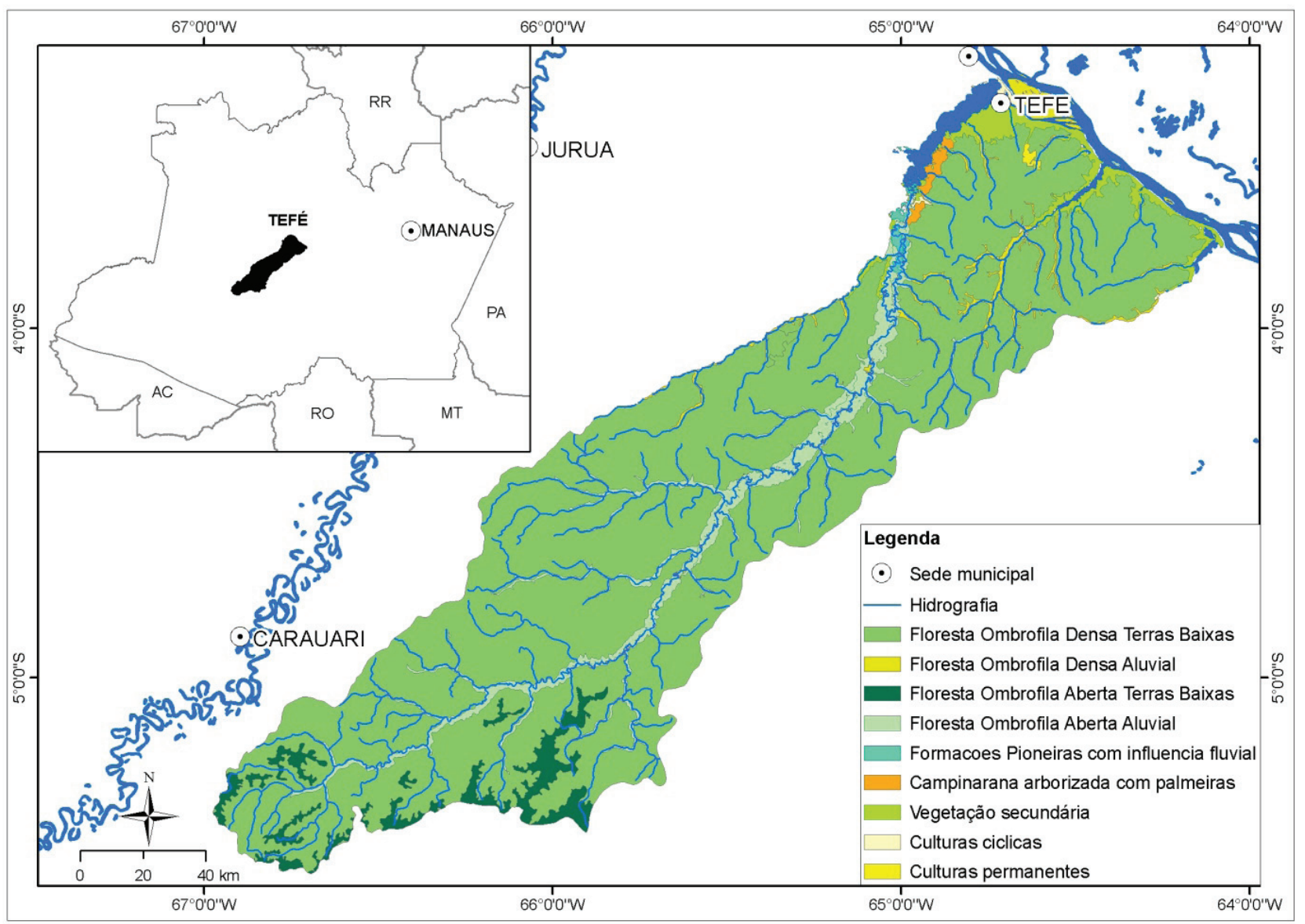

FIGURA 1: Localização do município de Tefé, AM e uso e cobertura da terra do município. Fonte: Compilado de CENSIPAM (2005).

limita suas possibilidades de acesso a fluvial e aéreo.

O clima da região de Tefé pode ser classificado, segundo a classificação de Köppen, como do tipo $A f i$, tropical chuvoso, sem estação seca (totais mensais de chuva acima de $60 \mathrm{~mm}$ ), regime térmico sem estação fria, com temperaturas médias mensais acima de $18^{\circ} \mathrm{C}$ e oscilação anual de temperatura inferior a $5^{\circ} \mathrm{C}$ (EMBRAPA, 1999). As temperaturas máxima e mínima oscilam entre $32^{\circ} \mathrm{C}$ e $21^{\circ} \mathrm{C}$, respectivamente, e a precipitação pluviométrica entre 2.300 e $2.700 \mathrm{~mm}$. A característica principal é a presença de um período chuvoso, estendendo-se em geral de dezembro a maio, e um período de estiagem, que se prolonga de junho a novembro (FIGURA 2). 


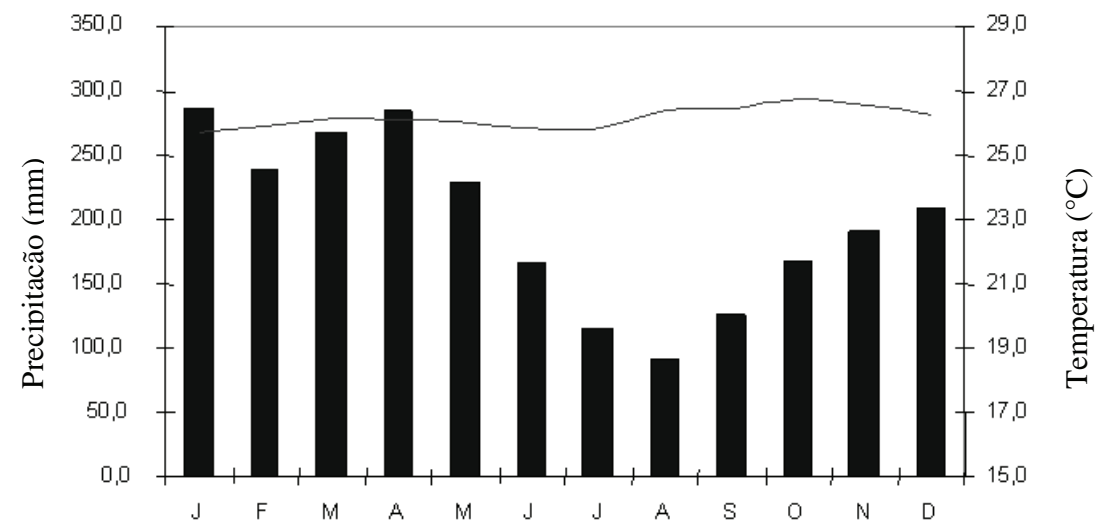

FIGURA 2: Distribuição da precipitação e temperaturas médias do município de Tefé, AM. Fonte: Ataíde et al. (2004).

Tefé está localizado em uma região onde as principais unidades geológicas são Depósitos Aluvionares e Formação Içá (CPRM, 2005). Os Depósitos Aluvionares datam do Quaternário (Holoceno) são representados por areias, siltes e argilas inconsolidadas, correspondentes aos depósitos recentes de planícies fluviais, por vezes, apresentando mais litificados e arenitos ferruginosos com seixos de quartzo arredondados com aspecto conglomerático (EMBRAPA, 1999). A Formação Içá apresenta morfologia em colinas muito suaves, com drenagem densa desenvolvida em padrão dentrítico a subdendrítico, menos comumente em treliça, contendo tributários numeroso, longos a curtos, bem definidos e arranjados de forma relativamente fechada (ROSSETI et al., 2007). A
Formação Içá, com espessuras em geral inferiores a $25 \mathrm{~m}$ em escala de afloramento, é composta por arenitos, argilitos e conglomerados (EMBRAPA, 1999). Em Tefé, as principais ordens de solos são Argissolo, Gleissolo, Plintossolo e Neossolo Flúvico (Solo aluvial).

A maior parte da superfície de Tefé (FIGURA 1) está coberta por Floresta Ombrófila Densa de Terras Baixas (82,16\%) (TABELA 1), seguido pela Floresta Ombrófila Aberta Aluvial (6,32\%) e Floresta Ombrófila Aberta Terras Baixas (3,48\%) (CENSIPAM, 2005). Em Tefé também é possível identificar Campinaranas, formações pioneiras com influencias fluvial e vegetação secundária (TABELA 1 e FIGURA 1). As áreas alteradas com culturas ou ocupação

TABELA 1: Área dos principais uso e cobertura da terra no município de Tefé/AM.

\begin{tabular}{lr}
\hline Uso e cobertura da terra & Área $\left(\mathrm{km}^{2}\right)$ \\
\hline Floresta Ombrófila Densa Aluvial & 470,324 \\
Floresta Ombrófila Densa Terras Baixas & $19.474,535$ \\
Floresta Ombrófila Aberta Aluvial & $1.497,527$ \\
Floresta Ombrófila Aberta Terras Baixas & 825,089 \\
Campinarana arborizada com palmeiras & 84,986 \\
Formações Pioneiras com influencia fluvial & 66,345 \\
Vegetação secundária & 566,547 \\
Culturas permanentes & 25,671 \\
Culturas cíclicas & 35,589 \\
Urbano & 1,596 \\
Água & 656,282 \\
\hline Total & $23.704,491$ \\
\hline
\end{tabular}

Fonte: Adaptado de CENSIPAM (2005). 
A problemática dos resíduos sólidos urbanos em Tefé, Amazonas Alexandre Donato da Silva, Eduardo da Silva Pinheiro

urbana representam apenas $0,27 \%$ da área do município (TABELA 1). Os dados do Instituto Nacional de Pesquisas Espaciais (INPE, 2009), para o ano de 2008, apontam Tefé no $21^{\circ}$ lugar de desflorestamento no Estado do Amazonas, com $608.6 \mathrm{~km}^{2}$ o que representa 3\% da área municipal.

No ano de 2007, a população de Tefé era de 62.920 habitantes, segundo resultados da contagem da população realizada pelo IBGE (2009a), sendo 47.257 habitantes da área urbana e 15.663 na área rural. Para o ano de 2008 a população estimada no município era de 64.703 habitantes (IBGE, 2009b). O município de Tefé apresenta a sexta maior população total do Estado do Amazonas.

As atividades urbanas do município são intensas, o que confere a Tefé o status de cidade pólo da região (SCHOR et al., 2007). Sua importância geopolítica, observada ao longo da história, possibilitou a presença de órgãos e instituições ausentes na maioria dos municípios do Amazonas. Dentre estes é possível citar a presença de um Comando de Brigada do Exército Brasileiro, Agência Fluvial da Marinha do Brasil, destacamento da Aeronáutica (Destacamento de Controle do Espaço Aéreo de Tefé - DTCEA-TF), Delegacia da Polícia Federal, Instituto Brasileiro do Meio Ambiente e dos Recursos Naturais Renováveis (IBAMA), Fórum de Justiça, Delegacia da Justiça do Trabalho, campus da Universidade do Estado do Amazonas / Centro de Estudos Superiores de Tefé (UEA/ CEST) e $3^{\circ}$ Batalhão de Polícia Militar do Amazonas, entre outros.

A presença desses órgãos e instituições é acompanhada de uma corrente circulação de capital, sendo a rede comercial local diversificada, abastecida principalmente por Manaus. Além do comércio e prestação de serviços, no Setor Terciário, se verificam atividades relevantes no Setor Primário principalmente representado pela agricultura, e no Setor Secundário pela indústria da pesca e móveis. A indústria da pesca em Tefé conta com a presença de um frigorífico de grande porte que abastece, inclusive, a mercados no exterior, principalmente Colômbia, havendo a presença constante de pequenos frigoríficos flutuantes, geralmente de proprietários estrangeiros oriundos da Colômbia e Peru (SILVA, 2009).

\section{Procedimentos metodológicos}

Para definir as alternativas locacionais para instalação de um aterro sanitário em Tefé/AM foram empregados os dados cartográficos e tabulares, disponíveis para o município, a saber:

- Base cartográfica do Serviço Geológico do Brasil (CPRM, 2005) em escala 1:250.000 contendo o limite e sede municipal, geologia e hidrografia;

- Base cartográfica do Centro Gestor e Operacional do Sistema de Proteção da Amazônia (SIPAM) em escala 1:250.000 contendo os mapas de solos e vegetação;

- Mapa de declividades gerado a partir do Modelo Digital de Elevação (MDE) da missão Shuttle Radar Topography Mission (SRTM) e processado por Valeriano (2008);

- Imagem do sensor Thematic Mapper (TM) do satélite LANDSAT-5 de 12/09/2008 com as bandas espectrais: vermelho $(0,63$ a $0,69 \mu \mathrm{m})$, infravermelho próximo $(0,76$ a $0,90 \mu \mathrm{m})$ e infravermelho médio $(1,55$ a $1,75 \mu \mathrm{m})$ e resolução espacial de $30 \mathrm{~m}$;

- Imagem do satélite QuickBird de 24/10/2004 com resolução espacial de $0,6 \mathrm{~m}$;

- Dados da estimativa da população de Tefé em 2008 (IBGE, 2009b);

- Dados dos resíduos sólidos gerados no município em 2008.

Os procedimentos metodológicos, utilizados para indicação das alternativas locacionais do aterro sanitário, foram realizados a partir da compilação de pesquisas feitas por Calijuri et al. (2002), Rocha et al. (2004) e Moreira et al. (2008), os quais empregaram análises multicritério com base em Geotecnologias. Os procedimentos estão resumidos no fluxograma da FIGURA 3. Os critérios selecionados basearamse, por sua vez, em aspectos normatizadores (NBR 13896, ABNT/1997), ambientais e de disponibilidade de infraestrutura no município, de acordo com as recomendações de Rocha et al. (2004). É importante citar que alguns critérios, normalmente descritos na literatura para instalação de aterros sanitários não foram considerados neste trabalho devido à carência 


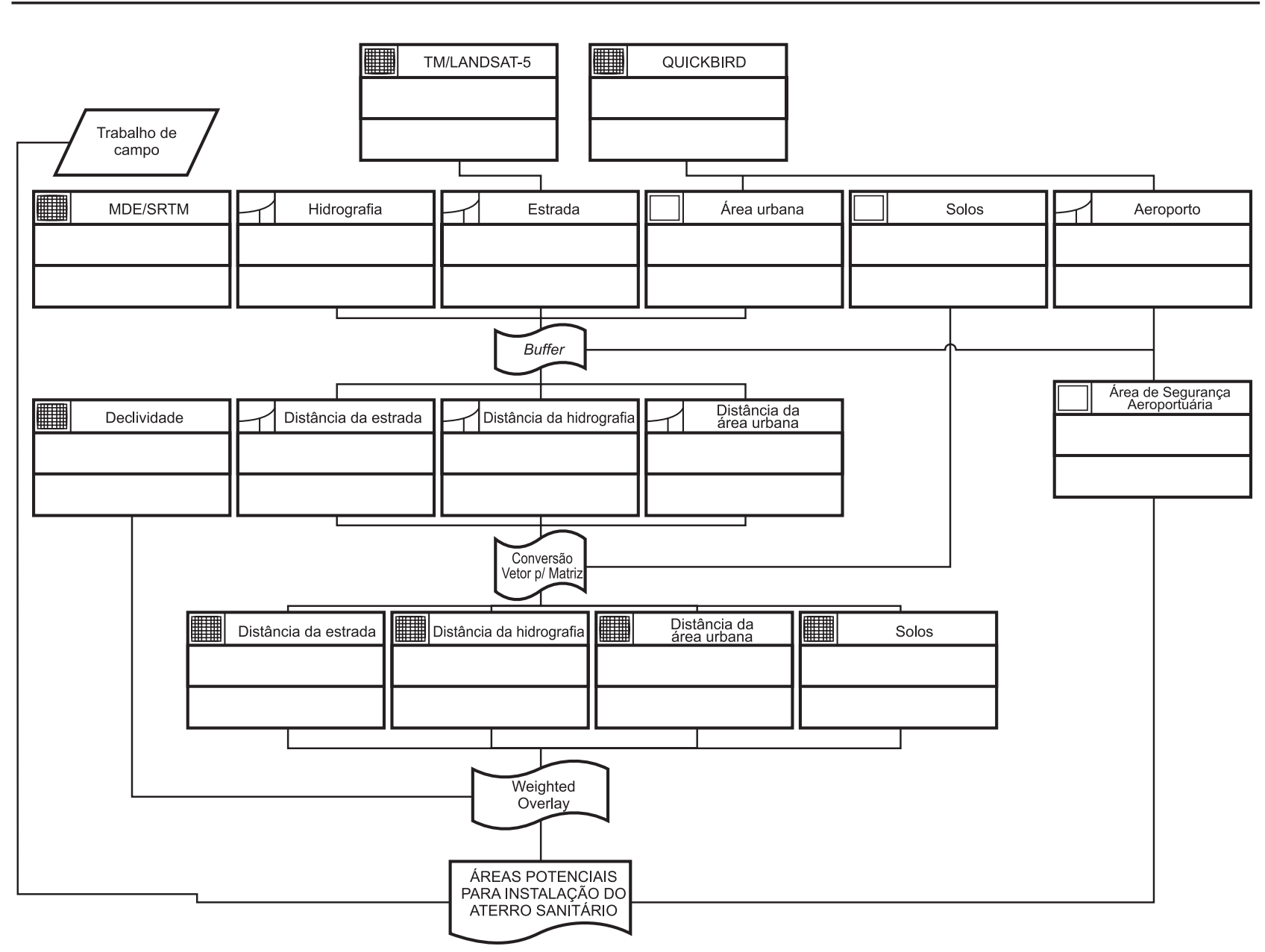

FIGURA 3: Fluxograma dos procedimentos utilizados no estudo em modelagem OMT-G (Object Modeling Techniques - Geographical).

de dados disponíveis para municípios do interior do Amazonas, especialmente quando as bases cartográficas.

A análise multicritério utilizada foi a superposição ponderada (Weighted overlay) disponível no software ArcGIS 9.3. Esta técnica agrega e pondera valores diversos para possibilitar uma análise integrada de múltiplos dados (mapas) envolvidos em uma mesma problemática (ESRI, 2008).

A imagem TM/LANDSAT-5 foi georreferenciada por meio do modelo polinomial de $1^{\circ}$ grau e interpolação por vizinho-mais-próximo, os pontos de controle foram obtidos na base cartográfica do CPRM em escala 1:250.000, o erro médio quadrático do processamento foi de 0,45 pixels.

O mapa de estradas de Tefé foi obtido a partir da interpretação visual da imagem TM/LANDSAT e digitalização na tela do computador em uma escala média de 1:60.000. Os mapas da área urbana e aeroporto do município também foram gerados pela mesma técnica, contudo nesta etapa foi utilizada a imagem QuickBird em uma escala média de 1:20.000.

A Área de Segurança Aeroportuária (ASA) foi mapeada por meio do cálculo de mapa de distâncias (Buffer), esta técnica permite gerar análise de proximidade em variáveis geográficas. De acordo com a Resolução CONAMA n ${ }^{\circ}$ 04/95, o aeroporto de Tefé está na categoria do item I: "São consideradas Área de Segurança Aeroportuária (ASA) as áreas abrangidas por um determinado raio a partir do centro geométrico do aeródromo, de acordo com seu tipo de operação, divididas em 2 (duas) categorias: I - raio de $20 \mathrm{~km}$ para aeroportos que operam de acordo com as regras de vôo por instrumento (IFR); e II - raio de 13 km para os demais aeródromos".

A Resolução CONAMA n 04/95 também des- 
creve as atividades consideradas perigosas para aeroportos, a saber: "dentro da ASA não será permitida implantação de atividades de natureza perigosa, entendidas como 'foco de atração de pássaros', como por exemplo, matadouros, curtumes, vazadouros de lixo, culturas agrícolas que atraem pássaros, assim como quaisquer outras atividades que possam proporcionar riscos semelhantes à navegação aérea".

Para os mapas de estrada, hidrografia e área urbana foram gerados mapas de distância de acordo com os critérios estabelecidos pela NBR 13896 (ABNT, 1997) e por Rocha et al. (2004). Posteriormente, foi aplicada a técnica da superposição ponderada e atribuídos diferentes fatores de influência e pesos, de acordo com a importância conferida a cada mapa (declividade, solos, distância da estrada, distância da área urbana, distância da hidrografia) para escolha das áreas potenciais para instalação do aterro sanitário. $\mathrm{O}$ mapa da Área de Segurança Aeroportuária foi sobreposto ao mapa final para verificar se as áreas definidas estavam contidas no raio de $20 \mathrm{~km}$ a partir do centro geométrico do aeródromo de Tefé.

A definição da área mínima para o aterro sanitário em Tefé foi estabelecida a partir dos dados de população e quantidade de resíduos gerados no município, considerando um mínimo de dez anos para a vida útil do aterro sanitário, a partir de 2008. A população do município para o ano de 2018 foi estimada por meio de uma progressão geométrica apresentada por Rocha et al. (2004), a saber:

$\mathrm{P}_{\mathrm{F}}=\mathrm{P}_{0} \cdot(1+\alpha)^{\mathrm{t}}$

onde:

$\mathrm{P}_{\mathrm{F}}=$ População ao final da vida útil do aterro (ano 2018)

$\mathrm{P}_{0}=$ População de Tefé em $2008=64.703$ habitantes (IBGE, 2009b)

$\alpha=$ Taxa de crescimento anual $=2,07 \%$ (SEPLAN/AM, 2009)

$\mathrm{t}=$ Tempo em anos.

$\mathrm{P}_{2008}=64.703(1+0,0207)^{10}$

$\mathrm{P}_{2018}=79.415,55$ habitantes

De acordo com a Prefeitura Municipal de Tefé, a produção per capita de resíduos sólidos no município, com base nos dados de 2008 é de $0,315 \mathrm{~kg} \cdot \mathrm{hab}^{-1}$. $\mathrm{dia}^{-1}$. Neste contexto, a quantidade de resíduos estimados para 2018 será:
$\mathrm{Q}_{2018}=79.415$ hab. $0,315 \mathrm{~kg} \cdot \mathrm{hab}^{-1} \cdot \mathrm{dia}^{-1}=25.013,12 \mathrm{~kg} \cdot \mathrm{dia}^{-1}$

Considerando que o peso específico $\left(\mathrm{P}_{\mathrm{e}}\right)$ dos resíduos sólidos urbanos compactados varia entre 500 a $700 \mathrm{~kg} \cdot \mathrm{m}^{-3}$ (HADDAD, 1994), o volume de resíduos sólidos (V) para será:

$\mathrm{V}=\mathrm{Q} / \mathrm{P}_{\mathrm{e}}=25.013,12 \mathrm{~kg} \cdot \mathrm{dia}^{-1} / 700 \mathrm{~kg} \cdot \mathrm{m}^{-3}=35,73 \mathrm{~m}^{3} \cdot \mathrm{dia}^{-1}$

$\mathrm{V}_{2018}=35,73 \mathrm{~m}^{3} \cdot \mathrm{dia}^{-1} .365$ dias. 10 anos $=130.425,54 \mathrm{~m}^{3}$

Um aterro sanitário deve atingir, após a compactação das camadas em células, uma altura variável entre três e seis metros (HADDAD, 1999). Para a maior segurança das águas subterrâneas no município de Tefé, levando em consideração a complexidade hídrica da região e o volume de chuvas anuais, optou-se por estabelecer valas de três metros de profundidade. Assim, o tamanho de área mínima para o aterro sanitário de Tefé será:

$\mathrm{S}_{\min }=\mathrm{V} / \mathrm{h}_{\max }=130.425,54 \mathrm{~m}^{3} / 3 \mathrm{~m}=43.475,1793 \mathrm{~m}^{2}=4,35 \mathrm{ha}$.

Considerando a necessidade de criar no complexo do aterro sanitário "unidades de apoio" (MONTEIRO et al., 2001), recomenda-se um incremento de $20 \%$ ou $40 \%$ sobre o tamanho da área necessária para a disposição dos resíduos (João Bosco Ladislau de Andrade, comunicação pessoal), o que totaliza a necessidade mínima de uma área com 5,22 ha para a construção do aterro sanitário em Tefé.

\section{RESULTADOS E DISCUSSÃO}

Os resíduos sólidos urbanos em Tefé

O serviço de coleta de resíduos sólidos em Tefé é administrado pela Prefeitura Municipal por meio das Secretarias de Meio Ambiente e de Infraestrutura. A coleta atinge a todos os bairros mais as Vilas da Marinha e Aeronáutica, e recolhe os resíduos de origem domiciliar, comercial, industrial e hospitalar, produzidos no município, incluindo o entulho. Atualmente, os resíduos sólidos urbanos de Tefé são depositados em um aterro controlado. Segundo a ABRELPE (2009), o aterro controlado representa um local no qual não são aplicadas todas as técnicas necessárias para assegurar 
a efetiva proteção ao ambiente e à saúde pública, configurando uma solução inadequada para disposição final dos resíduos.

Para a coleta dos resíduos sólidos são empregados cinco caminhões caçamba e um bote de alumínio para os bairros localizados além dos cursos d'água e área de concentração de flutuantes. Os caminhões circulam com os resíduos expostos, impropriamente, contudo representam a única opção. Estudos realizados sobre a possibilidade de utilização de caminhões compactadores de lixo, ideais para esse fim, apontaram para um resultado negativo devido ao formato e pavimentação das ruas de Tefé que não oferecerem bases resistentes aos eixos de rolamentos desse tipo de veículo (Prefeitura Municipal de Tefé - PMT, 2005).

Os resíduos sólidos e entulhos são coletados em sete rotas distintas, além das particulares, que operam toda a semana de segunda-feira a domingo. Não há coleta sistematizada em quatro bairros (Abial, Colônia Ventura, N. S. de Fátima e Vila Nova), há sérias dificuldades estruturais para a coleta de resíduos em dois bairros (São José e Nova Esperança) e em parte de outros dois (São João e Jerusalém) (SILVA, 2007). Segundo PMT (2009), tiveram destino ao aterro controlado do município, durante o ano de 2008 , aproximadamente 7.438,4 toneladas de resíduos sólidos urbanos. Desse total, 191,5 toneladas de resíduos foram reaproveitadas, não somado volume no aterro controlado. Dessa forma, 7.224,45 toneladas foram dispostas no aterro, uma média de mensal de 602 toneladas e média diária de cerca de 20,07 toneladas.

Os resíduos sólidos de serviço de saúde são coletados à parte, por viatura e pessoal específicos para esse fim. Além de farmácias, consultórios médicos, odontológicos e veterinários, Tefé possui seis Centros de Saúde administrados pela PMT. Os resíduos sólidos de serviço de saúde produzido pelo Posto Médico do Exército, por ter um baixo volume, são levados a alguma unidade de saúde por onde passa o serviço de coleta de lixo da PMT. Em 2008, foram coletadas 22 toneladas de resíduos sólidos de serviço de saúde em Tefé. Apesar do controle, o planejamento nem sempre é executado conforme previsto por fatores que vão desde problemas mecânicos com os caminhões à utilização dos mesmos para outros fins (SILVA, 2007).

Quanto às despesas, a Prefeitura Municipal in- formou que são empregados cerca de R \$ 200.000,00 (duzentos mil reais) mensais no serviço de coleta dos resíduos sólidos municipais. Estes distribuídos entre custos de pagamento de pessoal (cerca de cem pessoas), manutenção de caminhões, máquinas e embarcações, combustível, equipamentos, projeto de compostagem do aterro controlado e apoio à cooperativa de catadores que lá atua, entre outros gastos eventuais.

Os resíduos sólidos produzidos no aeroporto de Tefé recebem tratamento diferenciado. A Empresa Brasileira de Infraestrutura Aeroportuária (INFRAERO) mantém um depósito para resíduos recicláveis, onde são dispostos de forma seletiva e regularmente coletados por empresas que compram o material segundo seu valor por quilo. Os resíduos orgânicos são enterrados em área para esse fim, enquanto os demais resíduos, em volume bastante reduzido ao da produção original, são destinados no aterro controlado de Tefé, conduzidos por viatura da própria INFRAERO. O serviço de coleta e destinação dos resíduos sólidos produzidos no aeroporto de Tefé também não encontra dificuldades para a sua execução.

O fato da área urbana de Tefé estar situada entre cursos d'água, o lago de Tefé e o igarapé do Xidarini, faz com que grande parte de sua área esteja exposta ao regime de seca e cheia dos rios (FIGURA 4). Ocupados impropriamente, esses locais não oferecem a infraestrutura necessária que permita a circulação dos caminhões do serviço de coleta de resíduos sólidos. As estações de seca e chuva, refletidas no regime das águas da região, influem substancialmente nas condições de transporte dos resíduos coletados na cidade para locais considerados próprios.

Ainda que a partir de 2006 a Prefeitura Municipal de Tefé tenha investido na transformação de lixão em um aterro controlado e, em consequência, na melhoria nas condições de disposição final dos resíduos sólidos urbanos, isso constatado inclusive pela própria INFRAERO, a atual localização do aterro controlado ainda contraria a legislação vigente no Brasil. Na $2^{\text {a }}$ Vara da Justiça Federal, em Manaus, encontra-se em aberto, desde 2004, o Processo Nr 2004.32.00.005878-9 (MPF/PRAM), de $1^{\circ}$ de fevereiro de 2005 , que trata sobre a exigência na adequação do local para a efetivação do serviço. Mais recentemente, pelo Processo Nr 2008.32.00.001507-1

Sociedade \& N atureza, U berlândia, 22 (2): 297-312, ago. 2010 


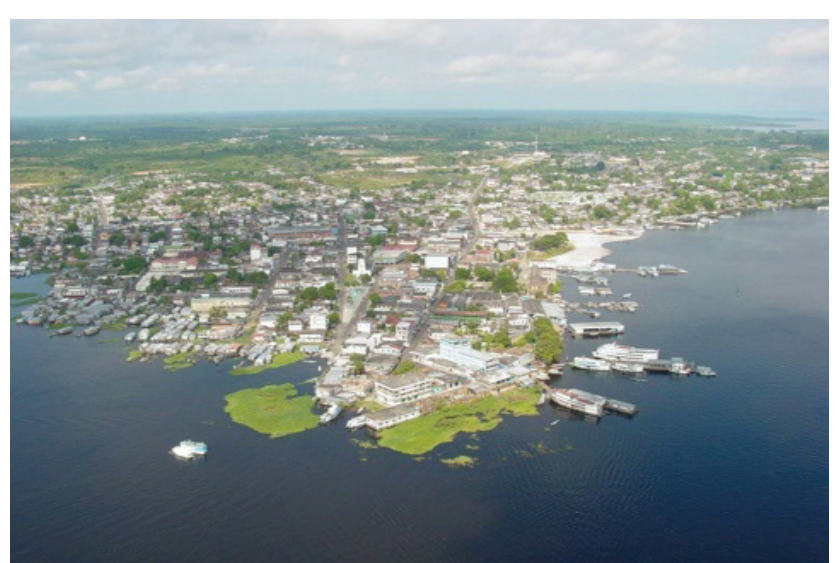

a

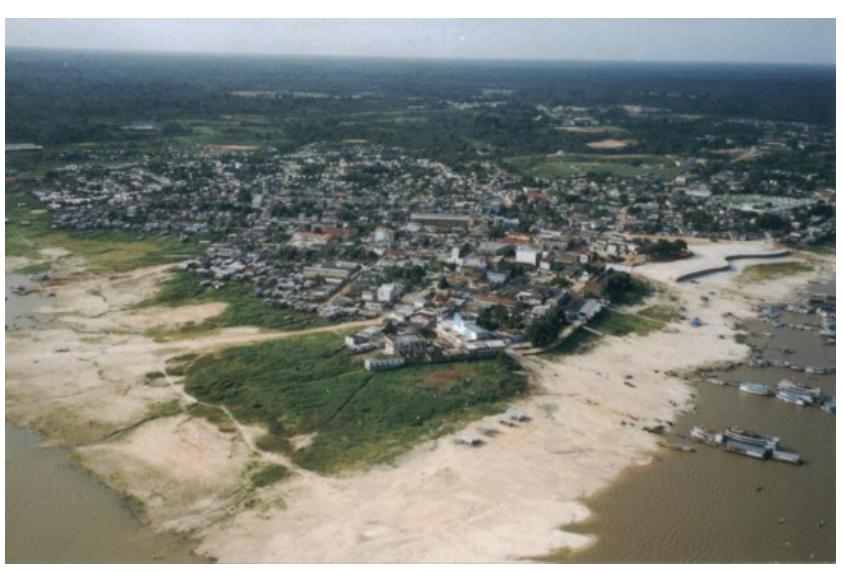

b

FIGURA 4: a) Área urbana de Tefé no período de cheia dos rios; b) Área urbana de Tefé no período de seca dos rios. Fonte: $16^{\text {a }}$ Brigada de Infantaria de Selva, 2003.

(MPF/PRAM), de 26 de março de 2008, o Prefeito Municipal de Tefé foi condenado por improbidade administrativa, ainda pela inadequação dos serviços de disposição final dos resíduos sólidos em Tefé. Atualmente, $\mathrm{o}$ aterro controlado continua localizado dentro da ASA do aeroporto local e, em consequência, a problemática persiste (NORMANDO, 2008).

Alternativas locacionais para a instalação de um aterro sanitário em Tefé

A técnica da superposição ponderada foi estruturada com a influência e o peso para cada mapa e suas respectivas classes temáticas (TABELA 2). Os resultados da análise multicritério apontaram nove alternativas locacionais para instalação do aterro sanitário em Tefé (FIGURA 5), as áreas variaram com tamanho de 4,67 a 195,81 hectares (TABELA 3).

Um dos fatores limitantes na escolha de áreas para construção de um aterro sanitário são os limites de um município, embora seja possível consórcio entre municípios para a solução comum deste problema. O mapa síntese das alternativas locacionais para instalação do aterro sanitário reduziu os $23.704 \mathrm{~km}^{2}$ de Tefé para uma área potencial de $8,7 \mathrm{~km}^{2}$ (TABELA 3 e FIGURA 5). Ainda que estes resultados não apon-

TABELA 2: Parâmetros utilizados como critérios para identificação de áreas potenciais para instalação do aterro sanitário.

\begin{tabular}{|c|c|c|c|}
\hline Mapas & Pesos (\%) & Classes & Notas \\
\hline \multirow{6}{*}{ Declividade } & \multirow{6}{*}{10} & $0-5 \%$ & 9 \\
\hline & & $5-12 \%$ & 9 \\
\hline & & $12-30 \%$ & 9 \\
\hline & & $30-47 \%$ & Restrito \\
\hline & & $47-100 \%$ & Restrito \\
\hline & & $>100 \%$ & Restrito \\
\hline \multirow{6}{*}{ Estradas } & \multirow{6}{*}{20} & $0-20 \mathrm{~m}$ & Restrito \\
\hline & & $20-50 \mathrm{~m}$ & Restrito \\
\hline & & $50-100 \mathrm{~m}$ & 7 \\
\hline & & $100-500 \mathrm{~m}$ & 9 \\
\hline & & $500-1000 \mathrm{~m}$ & 5 \\
\hline & & $>1000 \mathrm{~m}$ & Restrito \\
\hline \multirow{2}{*}{ Hidrografia } & \multirow{2}{*}{20} & $0-200 \mathrm{~m}$ & Restrito \\
\hline & & $>200 \mathrm{~m}$ & 9 \\
\hline \multirow{2}{*}{ Área urbana } & \multirow{2}{*}{10} & $0-2000 \mathrm{~m}$ & Restrito \\
\hline & & $>2000 \mathrm{~m}$ & 9 \\
\hline \multirow{4}{*}{ Solos } & \multirow{4}{*}{20} & Plintossolo & 9 \\
\hline & & Argissolo & 7 \\
\hline & & Gleissolo & Restrito \\
\hline & & Neossolo flúvico & Restrito \\
\hline
\end{tabular}




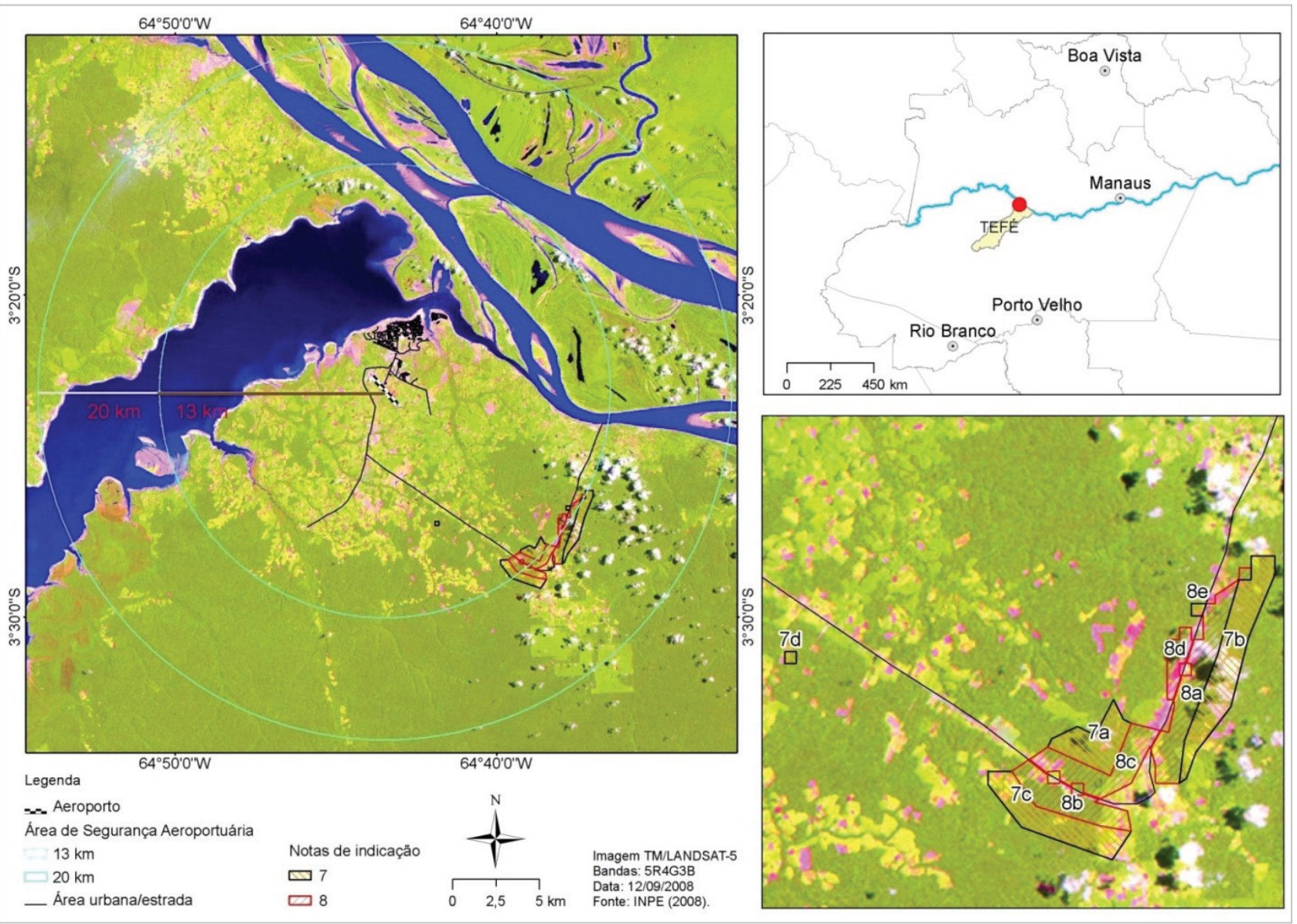

FIGURA 5: Mapa das alternativas locacionais para a instalação do aterro sanitário de Tefé/AM.

TABELA 3: Descrição das notas e tamanho das alternativas locacionais para instalação do aterro sanitário de Tefé/AM.

\begin{tabular}{lrr}
\hline Nota de indicação e local* & Perímetro $(\mathrm{m})$ & Área (ha) \\
\hline $7 \mathrm{a}$ & $4.708,78$ & 94,50 \\
$7 \mathrm{~b}$ & $9.655,45$ & 195,81 \\
$7 \mathrm{c}$ & $6.769,10$ & 138,53 \\
$7 \mathrm{~d}$ & 864,08 & 4,67 \\
$8 \mathrm{a}$ & $10.107,59$ & 171,84 \\
$8 \mathrm{~b}$ & $5.950,53$ & 104,88 \\
$8 \mathrm{c}$ & $7.046,53$ & 118,15 \\
$8 \mathrm{~d}$ & $3.455,47$ & 36,51 \\
8e & 945,90 & 5,43 \\
\hline Total & $49.503,43$ & 870,32 \\
\hline
\end{tabular}

* Locais apresentados no mapa da FIGURA 5.

tem exatamente o local para construção do aterro, explicado pela carência e escala de dados disponíveis, os resultados alcançados são importantes, uma vez que delimitam áreas menores para serem realizados 
estudos geotécnicos para instalação do aterro sanitário no município. Nesses estudos são realizadas análises como verificação da estabilidade dos taludes de escavação das jazidas de empréstimos dos solos, projeto de fundação das diversas estruturas (escritórios, oficinas, caixas de acumulação do chorume), projeto de escavação para a implantação de estruturas, projeto do sistema de impermeabilização de fundação para evitar a poluição do subsolo e das águas subterrâneas e estudo da geomecânica dos resíduos (BOSCOV, 2008).

Conforme os cálculos apresentados que resultaram na necessidade de área mínima de 5,22 ha para a instalação do aterro sanitário em Tefé, todas as alternativas locacionais mapeadas (FIGURA 5), com exceção da área $7 \mathrm{~d}$, apresentaram um tamanho suficiente para a disposição final dos resíduos sólidos urbanos produzidos em um período de 10 anos no município (TABELA 4). A técnica utilizada permitiu identificar diferentes notas às diferentes áreas potenciais, e cinco das oito áreas apontadas como possíveis para a construção do aterro receberam nota oito, as quais somaram 436,81 ha e três receberam nota sete totalizando 428,84 ha (FIGURA 5 e TABELA 3). Todas as alternativas locacionais que receberam nota oito como potenciais para instalação do aterro sanitário estão próximas de estradas pavimentadas, seja na estrada da Boa Vontade ou na estrada da Empresa Amazonense de Dendê (EMADE). Essas áreas foram apontadas na faixa de 50 a 500 metros de proximidade com as vias pavimentadas, uma vez que a faixa de até 50 metros foi considerada restrita para a instalação de aterros (TABELA 4).

As áreas que obtiveram nota sete como alternativas locacionais para instalação do aterro (FIGURA 5 e TABELA 3), também estão próximas das estradas Boa Vontade e EMADE, aproximadamente $700 \mathrm{~m}$. Estas alternativas locacionais estão mais distantes das estradas quando comparadas com as áreas que receberam nota oito. Para o aproveitamento adequado destas áreas seria necessária a construção de vias de acesso que oferecessem condições de tráfego durante todo o ano, conforme previsto na NBR 13896 (ABNT, 1997).

Para as distâncias das estradas foram estabelecidas seis classes, tornando restrita a possibilidade de que o aterro sanitário seja implantado exatamente nas margens da via ou a uma distância maior de 1000 metros (TABELA 2). A NBR 13896 (ABNT, 1997) enfatiza a importância das condições de acesso à área do aterro sanitário, este critério é importante para sua operação desde o projeto até o fechamento. No entanto, a Norma não estabelece distâncias mínimas das estradas, mas destaca que os acessos internos e externos devem permitir sua utilização sob quaisquer condições de tempo. Esse aspecto sugere que o aterro deve localizar- se próximo de vias pavimentadas. A distância mínima de $50 \mathrm{~m}$ das estradas pavimentadas (TABELA 3) foi estabelecida devido o acesso dos caminhões, a preocupação com o impacto visual e o acesso de pedestres à área do aterro. De outra forma a Norma refere-se à presença da vegetação como aspecto importante para impedir erosão, formação de poeira e transporte de odores, o que sugere a necessidade de uma faixa de vegetação no entorno do aterro.

As áreas apontadas com potencias para a instalação do aterro sanitário estão em uma distância média de $15 \mathrm{~km}$ do limite da área urbana municipal (FIGURA 5), o que indica resultados adequados segundo Gomes et al. (2001) que consideram ideais as distâncias entre 2 e $15 \mathrm{~km}$ a partir do centro gerador. Sobre essas distâncias os autores chamam a atenção para dois fatores opostos: quanto mais longe da cidade é o aterro, mais caro é o transporte, e quanto mais próximo o é, menor é a aceitação da população urbana.

Para análise da influência da área urbana foi adotada uma distância mínima de 2000m (TABELA 3), recomendada por Rocha et al. (2004), uma vez que o limite sul da área urbana está próxima da cabeceira do aeroporto de Tefé (1900 m) (FIGURA 5). O mapa da área urbana recebeu o peso de $10 \%$ de influência na análise multicritério, uma vez que são poucas as alternativas viárias para o afastamento do aterro da área urbana.

O município de Tefé possui o relevo suave ondulado, com declividades predominantes entre 0 a 5\%. Conforme recomendação da NBR 13896 (ABNT, 1997) foi estabelecida a declividade máxima de $30 \%$ para instalação do aterro sanitário (TABELA 2). Esta NBR fixa as condições mínimas exigíveis para projeto, implantação e operação dos aterros de resíduos não 
perigosos. As declividades receberam peso de $10 \%$ na análise multicritério (TABELA 2), devido às formas de relevo suave ondulado. É importante citar que as áreas próximas das estradas disponíveis no município apresentaram o máximo de $12 \%$ de declividade.

Outro fator importante na definição de áreas para instalação de aterros sanitários é a hidrografia, sendo necessário avaliar a influência do aterro na qualidade e no uso das águas superficiais e subterrâneas, devido à possível contaminação. As nove alternativas locacionais identificadas estão com distâncias maiores do que $200 \mathrm{~m}$ (TABELA 2), ou seja, de acordo com recomendação da NBR 13896 (ABNT, 1997). Esta NBR também indica uma permeabilidade inferior a $10-6 \mathrm{~cm} \cdot \mathrm{s}^{-1}$ nos solos para a implantação de aterros sanitários. A recomendação expressa a importância da manutenção das águas subterrâneas, uma vez que os solos que possuem grande permeabilidade permitem a contaminação dos lençóis freáticos pela possível percolação do chorume concentrado nos aterros sanitários. Neste contexto, os solos também são fatores importantes no processo de identificação de locais para instalação de aterro, por esse motivo, o mapa de solos recebeu peso de $20 \%$ (TABELA 2).

Com base na literatura especializada, descartaram-se as regiões com ocorrência dos Gleissolos e os Neossolos Flúvicos para a instalação do aterro sanitário em Tefé (julgados restritos) devido as suas características (hidromórficas, saturados de água e arenosos, respectivamente [LESPCH, 2002; LIMA et al., 2007]). Como mais favoráveis indicaram-se as regiões com ocorrência dos Plintossolos, em primeiro, e os Argissolos em segundo lugar (TABELA 3). Os Plintossolos apresentam restrição à percolação da água, além de textura argilosa a muito argilosa, presentes em terra firme, de relevo suave ondulado e plano o que indica, também, sua adequação às exigências da NBR 13896 (ABNT, 1997) sobre declividades. Os Argissolos apresentam grande aumento de argila em profundidade (LESPCH, 2002), sendo o teor considerado médio a alto. No entanto, na superfície o teor de argila é muito baixo, o que determina alta velocidade de infiltração tornando o solo altamente susceptível à erosão.

Os resultados obtidos para as alternativas locacionais para instalação do aterro em Tefé indicam que estes locais estão a uma distância menor do que $20 \mathrm{~km}$ do raio a partir do centro geométrico do aeroporto da cidade (FIGURA 5), ou seja, dentro da Área de Segurança Aeroportuária definida pela Resolução CONAMA n ${ }^{\circ} 04 / 95$. As áreas estão a uma distância média de $13 \mathrm{~km}$ do centro geométrico do aeroporto (FIGURA 4). Estes resultados sugerem mais um problema para a disposição final dos resíduos sólidos em Tefé.

As possibilidades de escoamento dos resíduos sólidos urbanos do município, a partir do centro gerador, estão limitadas à disponibilidade de estradas pavimentadas que permitam o acesso ao aterro sanitário durante todo o ano. Caso não fossem incluídos os 20 $\mathrm{km}$ de raio a partir do centro do aeroporto, todas as alternativas locacionais mapeadas não passariam do limite de $1 \mathrm{~km}$ a partir das estradas pavimentadas disponíveis.

A única possibilidade de afastar os locais para a disposição dos resíduos sólidos a mais de $20 \mathrm{~km}$ do centro geométrico do aeroporto em Tefé é a construção de nova estrada pavimentada que possa ser mantida em condições de tráfego durante todo o ano. Observando o mapa final gerado pela análise multicritério (FIGURA 5), constata-se que a nova estrada teria que ter, no mínimo, $7 \mathrm{~km}$ de extensão a partir da estrutura viária existente, isso no ponto mais próximo da possibilidade de afastamento. Esse ponto coincide com a localização da antiga EMADE, área já antropizada, com presença de vegetação secundária e solos considerados adequados para a construção do aterro sanitário (Plintossolo). Há, no entanto, nessa região várias famílias de agricultores e suas propriedades, e a construção de estrada para fins de acesso a um aterro sanitário pode ser contrário aos interesses daquelas populações, a exemplo do que já ocorreu em Tefé em outra região. Além disso, recentemente a imprensa publicou que empresa da Malásia, mediante acordo com o Governo do Estado do Amazonas, irá retomar as atividades da EMADE naquela localização (SILVA, 2009).

A escolha de outro ponto para a construção da estrada iria implicar em dois outros fatores complicadores. Em primeiro lugar, a estrada necessitaria ser mais extensa, fato que exigiria maior investimento econômico por parte da Prefeitura Municipal, tanto para a construção da via como para sua manutenção. O segundo aspecto, de cunho ambiental, demonstra 
que seria necessário desmatamento de grande parte do percurso da nova estrada a ser construída, uma vez que as demais áreas que possibilitam o afastamento da Área de Segurança Aeroportuária têm predominância de vegetação primária. Essa ação significaria grande impacto ambiental na região. Embora o desflorestamento seja um processo de natureza complexa para ser atribuído apenas a um único fator, a pavimentação de estradas e/ou a construção de vicinais (ramais) representa um dos principais vetores de desflorestamento na Amazônia (LAURANCE et al., 2001; FEARNSIDE, 2005).

Diante dessas constatações, a solução mais plausível para a problemática da disposição final dos resíduos sólidos urbanos em Tefé seria a realização de um acordo entre Prefeitura e INFRAERO, dentre outros órgãos envolvidos, no sentido de:

- Serem realizados estudos que levem em consideração as particularidades fisiográficas da região de Tefé, com vistas a investigar a possibilidade de se adotar como Área de Segurança Aeroportuária a distância de $13 \mathrm{~km}$ do centro geométrico do aeroporto, prevista para aeroportos que não operam de acordo com as regras de vôo por instrumento. Essa possibilidade permitiria que grande parte das áreas apontadas no mapa (FIGURA 5) pudessem ser aproveitadas para a instalação do aterro sanitário a um custo econômico e ambiental menores;

- A Prefeitura Municipal de Tefé planejar, implantar e operar o aterro sanitário de acordo com todos os critérios previstos na legislação ambiental referente a esta forma de disposição final dos resíduos sólidos urbanos e sob rigorosa fiscalização, especialmente no que tange a questão do perigo aviário. De outra forma, criar mecanismos para evitar o sobrevôo de aves na área do aterro sanitário, motivo pelo qual este tipo de empreendimento é considerado ameaça à navegação aérea.

\section{CONCLUSÃO}

O Brasil é um país de proporções continentais, dotado de características físicas e sociais variadas. Entretanto, a legislação ambiental brasileira não faz distinção em meio a essa diversidade e suas exigências não contemplam as particularidades ambientais regionais. Desse modo, suas exigências facilmente cumpridas em algumas regiões aparecem como complicações em outras.

Em outros lugares do Brasil, já foram demonstradas dificuldades quanto ao cumprimento da Resolução CONAMA n ${ }^{\circ}$ 04/95, mesmo em regiões possuidoras de extensa infraestrutura viária e áreas já degradadas, fatores que facilitam, naqueles locais, o escoamento e a disposição final dos resíduos sólidos urbanos.

Nas cidades amazônicas, porém, especialmente naquelas localizadas nas calhas dos rios, interligadas somente por hidrovias, a infraestrutura viária é limitada. Nas cidades dessa região que possuem aeroportos, para que se dê cumprimento à referida Resolução, é necessário que se causem significativos impactos ambientais como, por exemplo, a abertura de estradas para o afastamento de 13 ou $20 \mathrm{~km}$ do centro geométrico dos aeródromos. Além do impacto ambiental, o impacto econômico é também significativo, uma vez que se não forem pavimentadas e não receberem manutenção constante essas estradas ficam inutilizadas durante aproximadamente seis meses, na estação das chuvas.

De outra forma, paradoxalmente neste caso em particular, o cumprimento de uma Resolução ambiental dificulta cumprimento de outras, principalmente as que prescrevem restrições ao desmatamento, à degradação da fauna, flora e de áreas de conservação, entre outros aspectos.

As dificuldades encontradas em Tefé para o cumprimento da legislação são, desta forma, comuns às demais cidades das calhas dos rios amazônicos. Deve-se ressaltar que Tefé apresenta malha viária extraurbana atípica na região. Após o ano de 2008, há no município vias pavimentadas que, por vezes, não são encontradas na grande maioria dos municípios banhados pelos rios amazônicos. Ainda assim, não foi possível, a partir da disponibilidade atual de estradas encontrar um local para a instalação de aterro sanitário no município ao utilizar como critério a Área de Segurança Aeroportuária de $20 \mathrm{~km}$ de raio a partir do centro geométrico do aeroporto. As alternativas locacionais encontradas podem ser utilizadas desde que se considere a Área de Segurança Aeroportuária o raio de $13 \mathrm{~km}$ a partir do centro geométrico do aeroporto. 
Este trabalho não teve a pretensão de esgotar as possibilidades para a instalação do aterro sanitário de Tefé, mas discutir e apontar algumas alternativas locacionais a partir dos dados cartográficos e tabulares disponíveis para o município. Para afastar o local de instalação do aterro sanitário a uma distância maior do que $20 \mathrm{~km}$ do centro geométrico do aeroporto é necessária a construção de nova estrada pavimentada e nela manter as condições de tráfego durante todo o ano, o que implicaria em maiores custos econômicos e ambientais. É importante citar, além das variáveis analisadas neste estudo, que também são necessárias outras investigações que dependem de levantamentos de campo mais detalhados, principalmente em relação à situação fundiária do município e a aceitação, por parte da população próxima, da localização escolhida para a instalação do aterro sanitário.

É necessário, também, que estudos geotécnicos sejam realizados em cada uma das áreas apontadas para o levantamento das questões anteriormente referidas à instalação de aterro sanitário. Este estudo foi dirigido à questão espacial da problemática, levando em consideração, principalmente, os aspectos ambientais e legislativos na busca das alternativas locacionais, e com isso contribuir em nível de tomada de decisão. Isso não quer dizer que foram desconsideradas as questões sociais e esta é uma das principais preocupações intrínseca à análise. Avalia-se que os resultados obtidos neste estudo possam contribuir com a questão em outros municípios da região, uma vez que também apresentam problemas similares com a disposição final de seus resíduos sólidos.

\section{REFERÊNCIAS}

ANDRADE, J. L. de. Critérios aplicáveis em projetos de disposição final de resíduos sólidos na Amazônia Brasileira. In: CONGRESSO BRASILEIRO DE ENGENHARIA SANITÁRIA E AMBIENTAL, 24, 2007, Belo Horizonte. Anais... Belo Horizonte: FITABES, 2007.

ASSOCIAÇÃO BRASILEIRA DE EMPRESAS DE LIMPEZA PÚBLICA E RESÍDUOS ESPECIAIS (ABRELPE). Panorama dos resíduos sólidos no Brasil - 2008. São Paulo: ABRELPE, 2009.
ASSOCIAÇÃO BRASILEIRA DE NORMAS TÉCNICAS (ABNT). Apresentação de projetos de aterros controlados de resíduos sólidos urbanos (NBR 8849). Rio de Janeiro: ABNT, 1985.

Aterros de resíduos não perigosos: critérios para projeto, implantação e operação (NBR 13896). Rio de Janeiro: ABNT, 1997.

ATAIIDE, K. R. P.; BEZERRA, A. C.; RIBEIRO, J. B. M. Classificação climática da bacia do rio Urucu pelos métodos de Köppen e Thornthwaite. In: CONGRESSO BRASILEIRO DE METEOROLOGIA, 13, 2004, Fortaleza. Anais... Fortaleza, 2004.

BIANA, S. M. S. Seleção de áreas para implantação de aterros sanitários no município de Campina Grande-PB. 2007. 67f. Dissertação (Mestrado em Desenvolvimento e Meio Ambiente) - Universidade Federal da Paraíba. Campina Grande, 2007.

BIDONE, F. R. A.; POVINELLI, J. Conceitos básicos de resíduos sólidos. São Carlos: EESC/USP, 1999.

BOSCOV, M. E. G. Geotecnia ambiental. São Paulo: Oficina de Textos, 2008.

CALIJURI, M. L.; MELO, A. L. O.; LORENTEZ, J. F. Identificação de áreas para implantação de aterros sanitários com uso de análise estratégica de decisão. Informática Pública, v. 4, n. 2, p. 231-250, 2002.

CENTRO GESTOR E OPERACIONAL DO SISTEMA DE PROTEÇÃO DA AMAZÔNIA (CENSIPAM). Base cartográfica da Amazonia Legal. Escala 1:250.000, 2005.

CONSELHO NACIONAL DO MEIO AMBIENTE (CONAMA). Resolução $n^{\circ}$ 04/95. Disponível em: <http://www.mma.gov.br/port/conama/res/res95/ res0495.html $>$. Acesso em ago. 2006.

EMPRESABRASILEIRADE PESQUISAAGROPECUÁRIA (EMBRAPA). Levantamento de reconhecimento de média intensidade dos solos e avaliação da aptidão agrícola das terras do pólo Juruá-Solimões, 
Amazonas. Rio de Janeiro: Embrapa Solos, 1999. Boletim de Pesquisa, n. 2, 1999.

ENVIRONMENTAL SYSTEMS RESEARCH INSTITUTE (ESRI). ArcGIS Desktop help. Ver 9.3. ESRI, 2008.

FEARNSIDE, P. M. Desmatamento na Amazônia brasileira: história, índices e consequências. Megadiversidade, v. 1, n. 1, p.113-123, 2005.

GOMES, L. P.; COELHO, O.; ERBA, D.; VERONEZ, M. Critérios de seleção de áreas para disposição final de resíduos sólidos. In: ANDREOLI, C. (Org.), Resíduos sólidos do saneamento: processamento, reciclagem e disposição final. São Carlos: RIMA, 2001.

HADDAD, J. F. Disposição de lixo no solo, aterro sanitário e aterro controlado. Curso Latino-Americano de limpeza urbana e administração de resíduos sólidos. UERJ/Depto. de Engenharia Sanitária e Ambiental, Rio de Janeiro, 1994.

HADDAD, J. F. Projetos de aterros sanitários de resíduos sólidos urbanos e especiais. Indicadores operacionais. Análise de projeto para gestão integrada de resíduos sólidos urbanos. Associação Brasileira de Engenharia Sanitária e Ambiental (ABES). Rio de Janeiro, 1999.

INSTITUTO NACIONAL DE PESQUISAS ESPACIAIS (INPE). Projeto PRODES: Monitoramento da floresta amazônica brasileira por satélite. Disponível em: <http://www.obt.inpe.br/prodes/index.html $>$. Acesso em dez. 2009.

\section{INSTITUTO BRASILEIRO DE GEOGRAFIA E ES-} TATÍSTICA (IBGE). Contagens da população dos anos de 1996 e 2007. Disponível em: <http://www. ibge.gov.br>. Acesso em jul. 2009a.

. Estimativas das populações residentes, em $1^{\circ}$

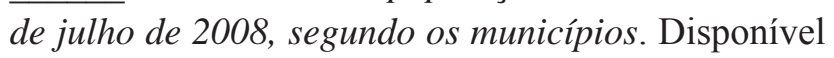
em: $<$ http://www.ibge.gov.br/. Acesso em jul. 2009b.

LAURANCE, W. F.; COCHRANE, M. A.; BERGEN,
S.; FEARNSIDE, P. M.; DELAMÔNICA, P.; BARBER, C.; D'ANGELO, S.; FERNANDES, T. The future of the brasilian Amazon. Science, v. 291, p. 438439, 2001.

LEPSCH, I. F. Formação e conservação dos solos. São Paulo: Oficina de Textos, 2002.

LIMA, H. N.; TEIXEIRA, W. G.; SOUZA, K. W. de. Os solos da paisagem da várzea com ênfase no trecho entre Coari e Manaus. In: FRAXE, T. J.; PEREIRA, H. S.; WITKOSKI, A. C. (Org.), Comunidades ribeirinhas Amazônicas: modos de vida e uso dos recursos naturais. Manaus, EDUA, 2007. p.35-52.

MONTEIRO, J. H. P.; FIGUEIREDO, C. E. M.; MAGALHÃES, A. F.; MELO, M. A. F. de; BRITO, J. C. X. de; ALMEIDA, T. P. F. de; MANSUR, G. L. Manual de gerenciamento integrado de resíduos sólidos. Rio de Janeiro: IBAM, 2001.

MOREIRA, M. A. A.; LORANDI, R.; MORAES, M. E. B. de. Caracterização de áreas preferenciais para a instalação de aterros no município de Descalvado (SP), na escala de 1:50.000. Revista Brasileira de Cartografia. v. 60, n. 2, p. 177-194, 2008.

NORMANDO, M. MPF/AM processa prefeito de Tefé por impobridade. Notícias do Ministério Público Federal. Brasília, 28 mar. 2008. Disponível em $<\underline{\text { http:// }}$ noticias.pgr.mpf.gov.br/noticias-do-site/patrimoniopublico-e-social/mpf-am-denuncia-prefeito-de-tefepor-improbidade/>. Acesso em ago. 2009.

PREFEITURA MUNICIPAL DE TEFÉ (PMT). Avaliação de processo: perigo aviário - visão municipal. Arquivo, Secretaria Municipal de Meio Ambiente (SEMMA), 2005.

Relatório anual de coleta de resíduos sólidos em Tefé - 2008. Secretaria Municipal de Meio Ambiente (SEMMA), 2009.

ROCHA, C. H. B.; FILHO, L. F. B.; SILVA, J. X. Geoprocessamento aplicado à seleção de locais para a implantação de aterros sanitários: o caso de Mangara- 
tiba - RJ. In: SILVA, J. X.; ZAIDAN, R.T (Org.), Geoprocessamento e análise ambiental. Rio de Janeiro: Bertrand Brasil, 2004. p. 259-299.

ROSSETTI, D. F.; GOÉS, A. M.; TOLEDO, P. M.; SANTOS JUNIOR, A. E. A.; PAZ, J. D. S. Reconstrução de paisagens pós-miocênicas na Amazônia Brasileira. In: ALBERNAZ, A. L. K. M. (Org.), Conservação da várzea: identificação e caracterização de regiões biogeográficas. Manaus: IBAMA/PróVárzea, 2008. p. 29-64.

SAMIZAVA, T. M.; KAIDA, R. H.; IMAI, N. N., NUNES, J. O. R. SIG aplicado à escolha de áreas potenciais para instalação de aterros sanitários no município de Presidente Prudente - SP. Revista Brasileira de Cartografia, v. 60, n. 1, p. 43-55, 2008.

SANTOS, J. S.; GIRARDI, A. G. Utilização de geoprocessamento para localização de áreas para aterro sanitário no município de Alegrete-RS. In: SIMPÓSIO BRASILEIRO DE SENSORIAMENTO REMOTO, 13, 2007, Florianópolis. Anais... Florianópolis: INPE, 2007.

SCHOR, T.; COSTA, D. P.da; OLIVEIRA, J. A. de. Notas sobre a tipificação da rede urbana na calha do rio Solimões, Amazonas. In: ENCONTRO NACIONAL DA ANPUR, 12, 2007, Belém. Anais... Belém, 2007.

SECRETARIA DE ESTADO DE PLANEJAMENTO E DESENVOLVIMENTO ECONÔMICO DO AMAZONAS (SEPLAN). Perfil Municipal - Tefé. Disponível em < $\underline{\text { http://www.seplan.am.gov.br/planejamen- }}$ to/ddr/Condensadov3/Conteudo/subregiao2/11-tefe.

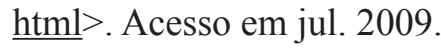

SERVIÇO GEOLÓGICO DO BRASIL (CPRM). Base cartográfica do Estado do Amazonas. Escala: 1:250.000, 2005.

SILVA, A. D. da. Coleta e destinação final do lixo urbano nas cidades da calha do rio Solimões e o perigo aviário: o estudo de caso de Tefé. 2007. 140f. Monografia (Especialização em Geografia da Amazônia
Brasileira), Universidade Federal do Amazonas, Manaus, 2007.

Geotecnologias e a problemática dos resíduos sólidos urbanos em Tefé, AM. 2009. 107f. Dissertação (Mestrado em Ciências do Ambiente e Sustentabilidade na Amazônia). Universidade Federal do Amazonas, Manaus, 2009.

SILVA, A.D. da; SCHOR, T. Quando o lixo sobe aos ares: o destino final dos resíduos sólidos urbanos nas cidades da calha do rio Solimões e o perigo aviário. In: FERREIRA, Y. N., NAKAGAWARA, Y.; YAMAKI, H.; PINESE, J. P. P.; SOARES, P. F. (Org.). Águas urbanas: memória, gestão, riscos e regeneração. Londrina: UEL, 2007 (no prelo).

TENÓRIO, J. A. S.; ESPINOSA, D. C. R. Controle Ambiental de Resíduos. In: PHILIP JR., A.; ROMÉRO, M. A.; BRUNA, G. C. (Ed.), Curso de Gestão Ambiental. Barueri: Manole, 2004.

WEBER, E.; HASENACK, H. Avaliação de áreas para instalação de aterro sanitário através de análises em SIG com classificação contínua dos dados. Porto Alegre: UFRGS, 2000. Disponível em: <http:// www.ecologia.ufrgs.br/labgeo/artigos/aterro.pdf $>$. Acesso em mar. 2009. 